\title{
Cancer-associated fibroblasts correlate with poor prognosis in rectal cancer after chemoradiotherapy
}

\author{
SUSUMU SAIGUSA ${ }^{1}$, YUJI TOIYAMA ${ }^{1}$, KOJI TANAKA $^{1,}$ TAKESHI YOKOE ${ }^{1}$, \\ YOSHINAGA OKUGAWA ${ }^{1}$, HIROYUKI FUJIKAWA ${ }^{1}$, KOHEI MATSUSITA $^{1}$, \\ MIKIO KAWAMURA $^{1}$, YASUHIRO INOUE ${ }^{1}$, CHIKAO MIKI $^{1}$ and MASATO KUSUNOKI ${ }^{1,2}$
}

Departments of ${ }^{1}$ Gastrointestinal and Pediatric Surgery and ${ }^{2}$ Innovative Surgery, Division of Reparative Medicine, Institute of Life Sciences, Mie University Graduate School of Medicine, 2-174 Edobashi, Tsu, Mie 514-8507, Japan

Received October 18, 2010; Accepted December 17, 2010

DOI: $10.3892 /$ ijo.2011.906

\begin{abstract}
Cancer-associated fibroblasts (CAFs) in the stroma play an important role in influencing the proliferation, invasion and metastasis of cancer cells. Fibroblast activation protein- $\alpha$ (FAP- $\alpha$ ) is known as a marker of CAFs, while stromal cell-derived factor-1 (SDF-1) is primarily expressed by CAFs. Herein, we investigated whether the expression levels of these genes are associated with clinical outcome after pre-operative chemoradiotherapy (CRT) in rectal cancer patients. We obtained total RNA from residual cancer stroma using microdissection from a total of 52 rectal cancer specimens from patients who underwent pre-operative CRT, we performed transcriptional analyses, and the serum protein concentrations in 40 matched microdissected specimens were measured by enzyme-linked immunosorbent assay. Additionally, we sought to clarify the location of FAP- $\alpha$ and SDF-1 expression using immunohistochemical staining. Of the 52 patients, 15.6 and $36.8 \%$ showed detectable FAP- $\alpha$ and SDF-1 mRNA expression, respectively. A significant correlation was observed between stromal FAP- $\alpha$ and SDF-1 mRNA levels. Moreover, there was a significant correlation between stromal SDF-1 gene expression levels and serum protein levels. Patients who developed distant recurrences after CRT had positive expression of both genes $(\mathrm{P}<0.05)$. The positive expression of both genes was also associated with poor probability of recurrence-free and overall survival $(\mathrm{P}<0.05)$. Patients with elevated serum SDF-1 levels had equally poor overall survival as those with positive stromal SDF-1 gene expression $(\mathrm{P}<0.05)$. In immunohistochemistry, both FAP- $\alpha$
\end{abstract}

Correspondence to: Dr Susumu Saigusa, Department of Gastrointestinal and Pediatric Surgery, Division of Reparative Medicine, Institute of Life Sciences, Mie University Graduate School of Medicine, 2-174 Edobashi, Tsu, Mie 514-8507, Japan E-mail: saigusa@clin.medic.mie-u.ac.jp

Key words: cancer-associated fibroblasts, fibroblast activation protein- $\alpha$, stromal cell-derived factor-1, rectal cancer, chemoradiotherapy and SDF-1 expression was observed in certain activated fibroblasts. In conclusion, FAP- $\alpha$ and SDF-1 expression was shown to be involved in tumor re-growth and recurrence in rectal cancer patients treated with pre-operative CRT.

\section{Introduction}

Rectal cancer is one of the most common cancers in Japan as well as in the western world. The introduction of pre-operative chemoradiotherapy (CRT) and total mesorectal excision (TME) in the management of rectal cancer has significantly decreased local recurrence rates and has improved patient survival. However, the rate of distant recurrent relapse remains as high as 15 to $20 \%$ in rectal cancer patients treated with pre-operative CRT followed by TME (1-3). The identification of predictive markers for distant recurrence should improve both clinical outcome and potential treatment stratification for such patients.

Over the years, the importance of the cancer stroma surrounding the tumor in the proliferation, invasion and metastasis of cancer cells has been increasingly recognized (4-7). For example, Finak et al investigated stromal gene expression in primary breast cancer and constructed a stromaderived prognostic predictor, which was independent from all standard prognostic factors (8). This result suggests the importance of the cancer stroma in tumor progression, and underscores the need for useful prognostic tumor stroma markers. Among stromal cells, cancer-associated fibroblasts (CAFs), which play an important role in tumor progression and regulate the microenvironment, have recently attracted attention.

Fibroblast activation protein- $\alpha$ (FAP- $\alpha$ ), also known as seprase, is a cell-surface serine protease. FAP- $\alpha$ is highly expressed in CAFs, but not in normal human tissue (9-11). Therefore, FAP- $\alpha$ is recognized as a marker for CAFs. FAP- $\alpha$ expression has been reported to be associated with tumor growth through the promotion of angiogenesis in breast cancer (12). Additionally, Lee et al reported that FAP- $\alpha$ expressed by CAFs has the potential to function as a tumor rejection antigen in many cancers in both in vitro and in vivo studies (13). 
Stromal cell-derived factor-1 (SDF-1), also known as the chemokine CXCL12, is primarily expressed by CAFs, and the expression of SDF-1 has been reported to be associated with the migration, invasion and proliferation of tumor cells $(7,14,15)$. SDF-1 is expressed by stromal cells, such as fibroblasts and endothelial cells (16). In colorectal cancer, elevated SDF-1 expression is associated with metastasis and poor prognosis $(17,18)$.

We investigated whether stromal FAP- $\alpha$ and SDF-1 expression levels are associated with clinical outcome, and whether these mRNA levels are correlated with their serum levels in patients with rectal cancer after CRT.

\section{Materials and methods}

Patients and specimens. From 2001 to 2008, 52 patients with rectal cancer (clinical stage II/III based on the TNM Classification established by the International Union Against Cancer) underwent pre-operative CRT followed by surgery at our institute. Post-CRT formalin-fixed, paraffin-embedded (FFPE) specimens were available for use in this study. Peripheral venous blood samples were obtained from 40 patients matched to microdissected specimens after CRT. Serum samples were allowed to clot and serum was stored at $-80^{\circ} \mathrm{C}$ until use. All patients signed informed consent forms for their tissues to be used in this study.

5-Fluorouracil-based chemoradiotherapy regimen. The chemoradiotherapy regimen included 4 cycles of 5 -fluorouracil (5-FU) given as a $24-\mathrm{h}, 600-\mathrm{mg} / \mathrm{m}^{2}$ continuous infusion, and tegafur-uracil (UFT) given $400 \mathrm{mg} / \mathrm{m}^{2}$ orally for 5 days, with concurrent $20-45$ Gy radiation, followed by resection. This regimen was based on the previously tested combination of continuous-infusion 5-FU plus UFT. The time interval between pre-operative CRT and surgery was 2-3 weeks in surgical patients (19). A total of 42 patients received shortcourse radiation at $20 \mathrm{~Gy}$ in 4 fractions over 1 week. The remaining 11 patients received conventionally fractionated radiation at a dose of $45 \mathrm{~Gy}$ in 25 fractions for 4 weeks. All patients underwent standard surgery including TME, and received 5-FU-based adjuvant chemotherapy after surgery for 6 months to 1 year.

Clinical response and histopathological tumor regression. The clinical response after pre-operative CRT was evaluated by barium enema, endoscopy and magnetic resonance imaging, and was then graded as complete response (CR), partial response (PR), no change (NC), or progressive disease (PD). The degree of histopathological tumor regression based on the Guidelines for the Clinical and Pathological Studies on Carcinoma of the Colorectum was classified into five categories: Grade 0 , no necrosis or regressive changes; grade 1a, more than two-thirds vital residual tumor cells (VRTCs); grade $1 \mathrm{~b}$, approximately one-third to two-thirds VRTCs; grade 2, fewer than one-third VRTCs; and grade 3, no VRTCs (20). We defined non-responders as histopathological tumor regression grade 0 to $1 \mathrm{~b}$, and responders as grade 2 and 3 .

Microdissection of FFPE specimens. FFPE specimens cut in $10-\mu \mathrm{m}$ sections were stained with nuclear fast red and subsequently manually microdissected to collect stromal cells separated from residual cancer cells with reference to hematoxylin and eosin slides.

RNA extraction from FFPE specimens. Microdissected samples were digested with proteinase $\mathrm{K}$ in lysis buffer containing Tris- $\mathrm{HCl}$, ethylenediaminetetraacetic acid, and sodium dodecyl sulfate, as previously described, with minor modifications (21). RNA was purified by phenol-chloroform extraction.

cDNA synthesis. cDNA was synthesized with random hexamer primers and SuperScript III Reverse Transcriptase (Invitrogen, Carlsbad, CA, USA) according to the manufacturer's instructions.

Quantitative real-time polymerase chain reaction (RT-PCR). Quantitative RT-PCR analysis was performed with the SYBRGreen PCR Master Mix (Applied Biosystems, Foster City, CA, USA) using the Applied Biosystems 7500 Real-Time PCR System according to the manufacturer's instructions. Primers for FAP- $\alpha$, SDF-1 and $\beta$-actin were designed with Primer3 software (Biology Workbench Version 3.2, San Diego Supercomputer Center, University of California, San Diego, CA). The following primer sequences were used: FAP- $\alpha-$ specific primers (sense, CACCTGATCGGCAATTTGTA; antisense, TTGGACGAGGAAGCTTT), SDF-1-specific primers (sense, ATGAACGCCAAGGTCGTG; antisense, ACATGGCTTTCGAAGAATCG), and $\beta$-actin (sense, ACAGAGCCTCGCCTTTGC; antisense, GCGGCGATATCA TCATCC). PCR was performed in a final volume of $25 \mu 1$ with SYBR-Green PCR Master Mix, using $1 \mu \mathrm{l} \mathrm{cDNA}$ and $400 \mathrm{nM}$ of each primer for the respective genes. Cycling conditions were $50^{\circ} \mathrm{C}$ for $2 \mathrm{~min}$ and $95^{\circ} \mathrm{C}$ for $10 \mathrm{~min}$, followed by 40 cycles at $95^{\circ} \mathrm{C}$ for $15 \mathrm{sec}$ and $60^{\circ} \mathrm{C}$ for $1 \mathrm{~min}$ each.

Relative expression levels of FAP- $\alpha$ and SDF-1. Relative gene expression levels were determined by the standard curve method. Standard curves and line equations were generated using 5-fold serially diluted solutions of cDNA from qPCR Human Reference Total RNA (Clontech, Mountain View, CA, USA) for FAP- $\alpha$ and SDF-1. All standard curves were linear in the analyzed range with an acceptable correlation co-efficient. The amount of target gene expression was calculated from the standard curve followed by quantitative normalization of cDNA in each sample using $\beta$-actin gene expression as the internal control. Target gene mRNA levels were described as ratios to $\beta$-actin mRNA levels. RT-PCR assays were performed in duplicate for each sample. Cases in which the $\beta$-actin mRNA level was unstable (not reliable) or not available were excluded from this study.

Serum FAP-1a and SDF-1 levels. We investigated whether FAP- $1 \alpha$ and SDF-1 mRNA expression levels in cancer stroma influenced serum FAP-1 $\alpha$ and SDF-1 protein levels by enzyme-linked immunosorbent assay (ELISA). FAP-1 $\alpha$ and SDF-1 concentrations were measured using ELISA kits for human FAP (catalog no: DY3715, R\&D Systems, Minneapolis, MN, USA) and human CXCL12/SDF-1 $\alpha$ (catalog no: DSA00, SSA00 and PDSA00, R\&D Systems), respectively, using the 
sandwich method. The lower limit of detection for serum FAP- $1 \alpha$ and SDF-1 concentration was $0.01 \mathrm{pg} / \mathrm{ml}$.

Immunohistochemistry for FAP- $\alpha$ and SDF-1. FFPE specimens were sliced into 2-3- $\mu \mathrm{m}$ sections. After deparaffinization and dehydration, specimens were brought to a boil in $10 \mathrm{mM}$ sodium citrate buffer for antigen unmasking. Specimens were then blocked and incubated with primary antibody overnight at $4^{\circ} \mathrm{C}$. The antibody was detected using Envision reagents (Envision kit/HRP, Dako Cytomation, Denmark). Primary monoclonal anti-human CXCL12/SDF-1 antibody (clone 79018, R\&D Systems) and rabbit polyclonal FAP- $\alpha$ antibody (ab53066; Abcam, Cambridge, MA, USA), were used at a dilution of 1:100, for implementation of the labeled streptavidin-biotin method (LASB2 kit/HRP, Dako Cytomation), and 3,3'-diaminobenzidine (Dako Cytomation). All sections were counterstained with hematoxylin, and were dehydrated and mounted. Negative controls were also run simultaneously.

Statistical analysis. All statistical analyses were done using Stat View 5.0 for Windows (SAS Institute Inc., Cary, NC, USA). The contingency tables were analyzed using the Chi-square test with Yates' correction. The correlations among mRNA levels and serum concentration were assessed with the Spearman rank correlation co-efficient. A nonparametric receiver operating characteristic (ROC) analysis was performed to calculate the best cut-off value for each serum level that would be predictive of distant recurrence and survival, using Medcalc 7.2 for Windows (Mariakerke, Belgium). Disease-free and overall survival probabilities were calculated using the Kaplan-Meier product limit method and intergroup differences were determined using the log-rank test. The influence of distant recurrence and survival predictors identified by univariate analysis was assessed by multivariate analysis using Cox's proportional hazards model. Two-sided P-values of $<0.05$ were considered to be statisticaly signficant.

\section{Results}

Patient and tumor characteristics. Fifty-two patients were included in this study. Their median age was 64 years (range, 37 to 78 years) and the male-to-female ratio was 4.2:1. Post-CRT pathological T stages were pT1 $(n=5)$, pT2 $(n=13)$, pT3 $(n=32)$ and pT4 $(n=2)$. Seventeen patients $(33 \%)$ had pathological lymph node metastases. Thirty-three patients $(64 \%)$ had post-operative stage I and II. Forty-four tumors (85\%) showed well- or moderately-differentiated adenocarcinoma histology. No patients had local failure. Patterns of distant recurrence included liver and lung metastases $(n=2)$, lung metastasis alone $(n=5)$ and peritoneal metastasis $(n=1)$. Histopathological tumor regression grades included grade $0(n=0)$, grade la $(n=11)$, grade $1 \mathrm{~b}(\mathrm{n}=25)$ and grade $2(\mathrm{n}=16)$ (Table I). The median follow-up period was 43 months (range, 14 to 105 months).

Stromal FAP- $\alpha$ and SDF-1 gene expression. Quantitative RT-PCR revealed that of the 52 patients, 7 (15.6\%) and 14 (36.8\%) showed detectable FAP- $\alpha$ and SDF-1 mRNA expression, respectively, in residual rectal cancer stroma after CRT, whereas the remaining patients had no detectable expression despite positive gene expression of $\beta$-actin. FAP- $\alpha$ and SDF- 1 mRNA
Table I. Patient and tumor characteristics.

\begin{tabular}{|c|c|}
\hline Variables & Number $(\%)$ \\
\hline \multicolumn{2}{|l|}{ Gender } \\
\hline Male & $42(81)$ \\
\hline Female & $10(19)$ \\
\hline \multicolumn{2}{|l|}{ Age (mean; 64.5 years) } \\
\hline$<65$ & $26(50)$ \\
\hline$\geq 65$ & $26(50)$ \\
\hline \multicolumn{2}{|l|}{$\mathrm{T}$ classification } \\
\hline $1 / 2$ & $17(33)$ \\
\hline $3 / 4$ & $35(67)$ \\
\hline \multicolumn{2}{|l|}{$\mathrm{N}$ classification } \\
\hline Absent & $35(67)$ \\
\hline Present & $17(33)$ \\
\hline \multicolumn{2}{|l|}{ Post-operative stage } \\
\hline $\mathrm{I} / \mathrm{II}$ & $33(64)$ \\
\hline III & $19(36)$ \\
\hline \multicolumn{2}{|l|}{ Lymphatic invasion } \\
\hline Absent & $13(25)$ \\
\hline Present & $39(75)$ \\
\hline \multicolumn{2}{|l|}{ Vascular invasion } \\
\hline Absent & $22(42)$ \\
\hline Present & $30(58)$ \\
\hline \multicolumn{2}{|l|}{ Histology } \\
\hline Well/moderate & $44(85)$ \\
\hline Poorly/signet/mucinous & $8(15)$ \\
\hline \multicolumn{2}{|l|}{ Pathological response } \\
\hline Non-responder, grade $0 / 1 \mathrm{a} / 1 \mathrm{~b}$ & $36(69)$ \\
\hline Responder, grade $2 / 3$ & $16(31)$ \\
\hline \multicolumn{2}{|l|}{ Distant recurrence } \\
\hline Absent & $44(85)$ \\
\hline Present & $8(15)$ \\
\hline
\end{tabular}

levels were $0.118 \pm 0.108$ (range, 0-5.633) and 0.2975 \pm 0.2665 (range, 0-13.86), respectively. Patients were divided into two groups according to the positivity of each gene expression.

Serum FAP- $\alpha$ and SDF-1 concentration in rectal cancer after $C R T$. Serum FAP- $\alpha$ and SDF-1 concentration in a total of 40 serum samples matched the microdissected specimens were measured by enzyme-linked immunosorbent assay. Serum concentrations of FAP- $\alpha$ and SDF-1 were $4.424 \pm 0.299 \mathrm{ng} / \mathrm{ml}$ (range, 0.362-6.477) and 2.580 $\pm 0.067 \mathrm{ng} / \mathrm{ml}$ (range, 1.763$3.404)$, respectively.

Association between FAP- $\alpha$ and SDF-1 expression levels and clinicopathological variables. Table II shows the association between FAP- $\alpha$ and SDF-1 gene expression levels and clinicopathological variables. Positive gene expressions of FAP- $\alpha$ and SDF-1 were significantly correlated with distant recurrence (FAP- $\alpha, \mathrm{P}=0.030$; and $\mathrm{SDF}-1, \mathrm{P}=0.014$, respectively). No significant correlation was noted between the positivity of these genes and other clinicopathological variables. In serum FAP-1 $\alpha$ and SDF-1 levels, no associations between the serum 
Table II. Association of FAP- $\alpha$ and SDF-1 gene expression with clinicopathological variables.

\begin{tabular}{|c|c|c|c|c|c|c|}
\hline \multirow[t]{2}{*}{ Variables } & \multicolumn{3}{|c|}{ FAP- $\alpha$ gene expression } & \multicolumn{3}{|c|}{ SDF-1 gene expression } \\
\hline & Negative & Positive & P-value & Negative & Positive & P-value \\
\hline \multicolumn{7}{|l|}{ Gender } \\
\hline Male & 37 & 5 & 0.500 & 30 & 12 & 0.583 \\
\hline Female & 8 & 2 & & 8 & 2 & \\
\hline \multicolumn{7}{|l|}{ Age (mean; 62 years) } \\
\hline$<65$ & 23 & 3 & 0.685 & 19 & 7 & $>0.9999$ \\
\hline$\geq 65$ & 22 & 4 & & 19 & 7 & \\
\hline \multicolumn{7}{|l|}{$\mathrm{T}$ classification } \\
\hline $1 / 2$ & 17 & 1 & 0.224 & 13 & 5 & 0.920 \\
\hline $3 / 4$ & 28 & 6 & & 25 & 9 & \\
\hline \multicolumn{7}{|l|}{$\mathrm{N}$ classification } \\
\hline Absent & 30 & 5 & 0.803 & 28 & 7 & 0.106 \\
\hline Present & 15 & 2 & & 10 & 7 & \\
\hline \multicolumn{7}{|l|}{ Post-operative stage } \\
\hline $\mathrm{I} / \mathrm{II}$ & 28 & 5 & 0.638 & 26 & 7 & 0.221 \\
\hline III & 27 & 2 & & 12 & 7 & \\
\hline \multicolumn{7}{|l|}{ Lymphatic invasion } \\
\hline Absent & 11 & 2 & 0.815 & 11 & 2 & 0.279 \\
\hline Present & 34 & 5 & & 27 & 12 & \\
\hline \multicolumn{7}{|l|}{ Vascular invasion } \\
\hline Absent & 20 & 2 & 0.429 & 16 & 6 & 0.961 \\
\hline Present & 25 & 5 & & 22 & 8 & \\
\hline \multicolumn{7}{|l|}{ Histology } \\
\hline Well/moderate & 38 & 6 & 0.931 & 31 & 13 & 0.317 \\
\hline Poorly/signet/mucinous & 7 & 1 & & 7 & 1 & \\
\hline \multicolumn{7}{|l|}{ Pathological response } \\
\hline Non-responder, grade $0 / 1 \mathrm{a} / 1 \mathrm{~b}$ & 30 & 6 & 0.310 & 25 & 11 & 0.376 \\
\hline Responder, grade $2 / 3$ & 15 & 1 & & 13 & 3 & \\
\hline \multicolumn{7}{|l|}{ Distant recurrence } \\
\hline Absent & 40 & 4 & 0.030 & 35 & 3 & 0.014 \\
\hline Present & 5 & 3 & & 9 & 5 & \\
\hline
\end{tabular}

Table III. Correlation among stromal mRNA level and serum concentration.

\begin{tabular}{lcc}
\hline & Spearman's $\varrho$ & P-value \\
\hline Stroma FAP- $\alpha$ mRNA/stroma SDF-1 mRNA & 0.760 & $<0.001$ \\
Stroma FAP- $\alpha$ mRNA/serum FAP- $\alpha$ concentration & 0.080 & 0.628 \\
Stroma SDF-1 mRNA/serum SDF-1 concentration & 0.337 & 0.036 \\
Serum FAP- $\alpha$ concentration/serum SDF-1 concentration & 0.127 & 0.440 \\
\hline
\end{tabular}

levels of these proteins and other clinicopathological variables were observed (data not shown).

Correlation between FAP- $\alpha$ and SDF-1 expression. A significant positive correlation was observed between FAP- $\alpha$ and SDF-1 gene expression levels in residual cancer stroma (Spearman's $\mathrm{Q}=0.760, \mathrm{P}<0.0001$ ). A significant correlation was also observed between the stromal SDF-1 mRNA level and serum SDF-1 concentration (Spearman's $\mathrm{Q}=0.337, \mathrm{P}=0.036$ ), but not between the FAP- $\alpha$ stromal mRNA level and serum FAP- $\alpha$ protein level (Table III).

Predictive value of FAP- $\alpha$ and SDF-1 expression levels for distant recurrence and survival. On the basis of these results, ROC analysis was used to identify each cut-off value of FAP- $\alpha$ and SDF-1 serum concentrations that was predictive of distant recurrence and survival. A non-parametric ROC analysis determined that the optimal cut-off values of FAP- $\alpha$ and 
Table IV. Uni- and multivariate analyses for predictors of distant recurrence and survival.

A, Predictors of distant recurrence

\begin{tabular}{lcc}
\hline Variables & Hazard ratio & 95\% CI \\
\hline Univariate analysis & & P-value \\
T classification (T1/2 vs. T3/4) & 0.244 & $0.134-3.322$ \\
N classification (absent vs. present) & 3.678 & $0.059-1.032$ \\
Post-operative stage (I/II vs. III) & 2.854 & $0.069-1.219$ \\
FAP- $\alpha$ gene expression (negative vs. positive) & 6.223 & $0.030-0.658$ \\
SDF-1 gene expression (negative vs. positive) & 7.478 & $0.018-0.517$ \\
Serum FAP- $\alpha$ ( $\geq$ cut-off vs. <cut-off) & 0.222 & $0.275-8.249$ \\
Serum SDF-1 ( $\geq$ cut-off vs. <cut-off) & 0.099 & $0.169-11.718$ \\
Multivariate analysis & & 0.095 \\
FAP- $\alpha$ gene expression (negative vs. positive) & 0.429 & $0.087-2.830$ \\
SDF-1 gene expression (negative vs. positive) & 4.159 & $0.020-0.925$ \\
\hline
\end{tabular}

B, Predictors of survival

\begin{tabular}{lcc}
\hline Variables & Hazard ratio & 95\% CI \\
\hline Univariate analysis & & P-value \\
T classification (T1/2 vs. T3/4) & 0.035 & $0.233-3.328$ \\
N classification (absent vs. present) & 2.913 & $0.108-1.166$ \\
Post-operative stage (I/II vs. III) & 6.022 & $0.050-0.715$ \\
Distant recurrence (absent vs. present) & 5.412 & $0.066-0.799$ \\
FAP- $\alpha$ gene expression (negative vs. positive) & 3.960 & $0.059-0.979$ \\
SDF-1 gene expression (negative vs. positive) & 8.181 & $0.044-0.558$ \\
Serum FAP- $\alpha$ ( $\geq$ cut-off vs. <cut-off) & 1.300 & $0.511-12.648$ \\
Serum SDF-1( $\geq$ cut-off vs <cut-off) & 3.053 & $0.019-1.256$ \\
Multivariate analysis & & 0.014 \\
Post-operative stage (I/II vs. III) & 6.165 & 0.047 \\
Distant recurrence (absent vs. present) & 0.040 & 0.004 \\
FAP- $\alpha$ gene expression (negative vs. positive) & 0.141 & 0.254 \\
SDF-1 gene expression (negative vs. positive) & 5.589 & $0.159-4.472$ \\
\hline
\end{tabular}

CI, confidence interval.

SDF-1 were 3.271 and $3.007 \mathrm{ng} / \mathrm{ml}$ for distant recurrence, and 5.448 and $2.397 \mathrm{ng} / \mathrm{ml}$ for survival. Cox's univariate proportional hazards analysis showed that positive FAP- $\alpha$ and SDF-1 gene expression in residual cancer stroma was significantly associated with a higher rate of developing distant recurrence after pre-operative CRT compared to negative cases $(\mathrm{P}=0.013$ and $\mathrm{P}=0.006$, respectively). In multivariate analysis, positive SDF-1 gene expression independently predicted distant recurrence after CRT followed by surgery ( $\mathrm{P}=0.041)$ (Table IVA). Regarding survival, Cox's univariate proportional hazard analysis showed that post-operative stage, distant recurrence, positive stromal SDF-1 and FAP- $\alpha$ gene expression were significantly associated with poor survival $(\mathrm{P}=0.014, \mathrm{P}=0.020$, $\mathrm{P}=0.004$ and $\mathrm{P}=0.047$, respectively). Cox's multivariate hazard model analysis showed that post-operative stage and positive stromal SDF-1 gene expression independently predicted poor survival $(\mathrm{P}=0.013$ and $\mathrm{P}=0.018$, respectively) (Table IVB).

As shown in Fig. 1A and B, patients with positive FAP- $\alpha$ and SDF-1 gene expression in cancer stroma tissue experi- enced significantly worse recurrence-free survival (FAP- $\alpha$, $\mathrm{P}=0.0038$; SDF-1, $\mathrm{P}=0.0008$ ). Moreover, the positive expression of both of these genes was significantly associated with poor overall survival (FAP- $\alpha, \mathrm{P}=0.0310$; SDF-1, $\mathrm{P}=0.0012$ ). Fig. $1 C$ and D show the association of each serum level with recurrence-free and overall survival. An elevated serum SDF-1 level was associated with poor overall survival $(\mathrm{P}=0.0442)$.

Immunohistochemical analysis of FAP- $\alpha$ and $S D F-1$ expression. As shown in Fig. 2, FAP- $\alpha$ and SDF-1 staining were detected not only in stromal tissue but also in residual cancer cells. FAP- $\alpha$ staining was present in the cytoplasm of residual cancer cells, stromal fibroblasts, endothelial cells and intravascular granules. SDF-1 expression was observed in the cytoplasm of residual cancer cells, as well as in stromal fibroblasts, endothelial cells and neural cells. FAP- $\alpha$ and SDF-1 expression was also observed in activated fibroblasts. In these fibroblasts, FAP- $\alpha$ expression was observed in the nuclei and cytoplasm, while SDF-1 was expressed in the cytoplasm. 

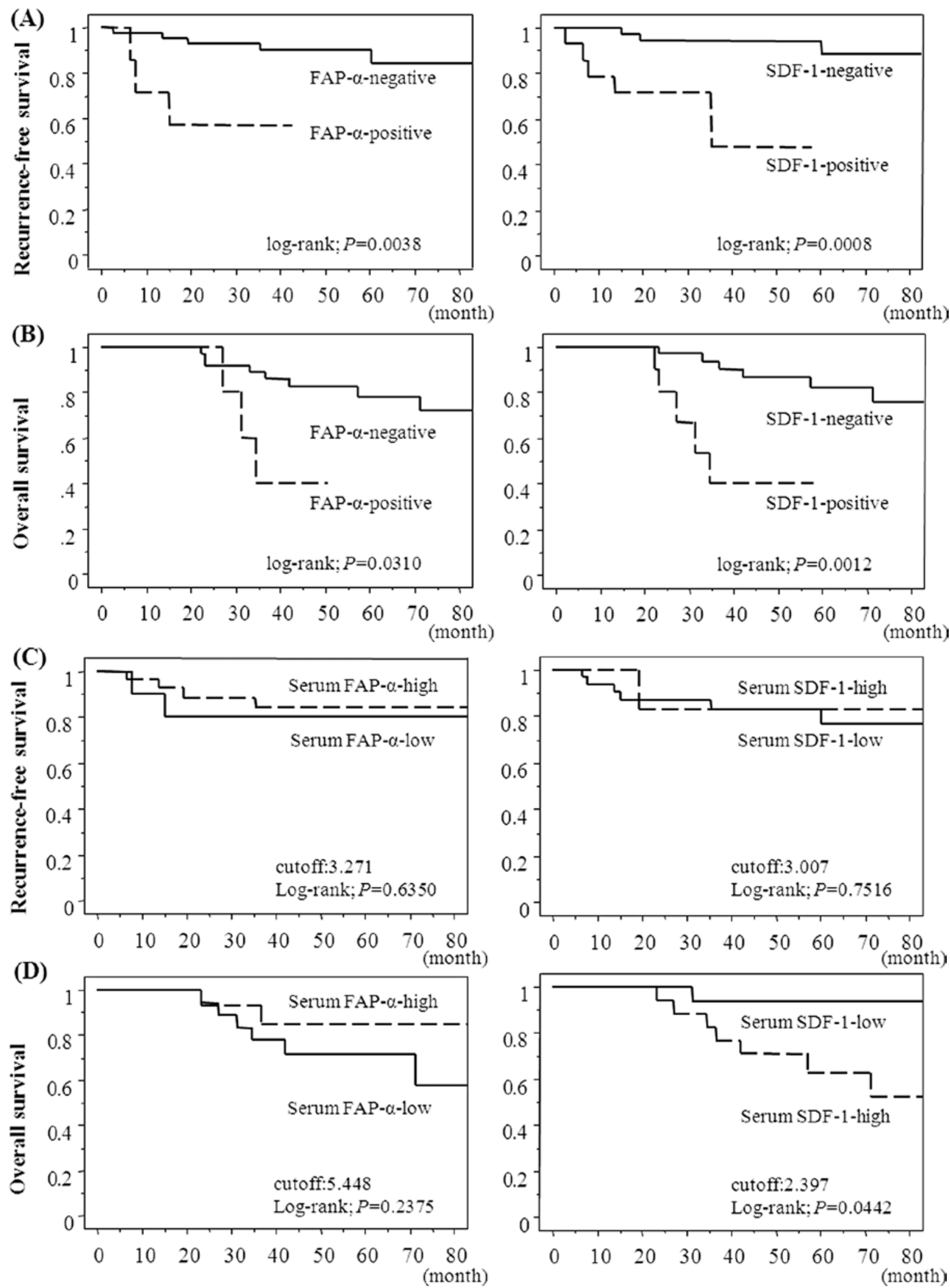

Figure 1. Recurrence-free survival (A) and overall survival (B) curves according to the positivity of FAP- $\alpha$ and SDF-1 mRNA expression in stromal tissue after CRT. Recurrence-free survival (C) and overall survival (D) curves in patients subdivided on the basis of serum FAP- $\alpha$ and SDF-1 levels using individual cut-off values.

\section{Discussion}

Over the years, the interaction between cancer and stromal cells in tumor growth, invasion and metastasis has become increasingly clear (4-6). Cancer tissue is composed not only of cancer cells but also of cancer-associated stromal cells, including extracellular matrix molecules, endothelial cells, fibroblasts and immune cells. CAFs have been reported to release potentially oncogenic signals such as the transforming growth factor- $\beta$ (TGF- $\beta$ ) and vascular endothelial growth 

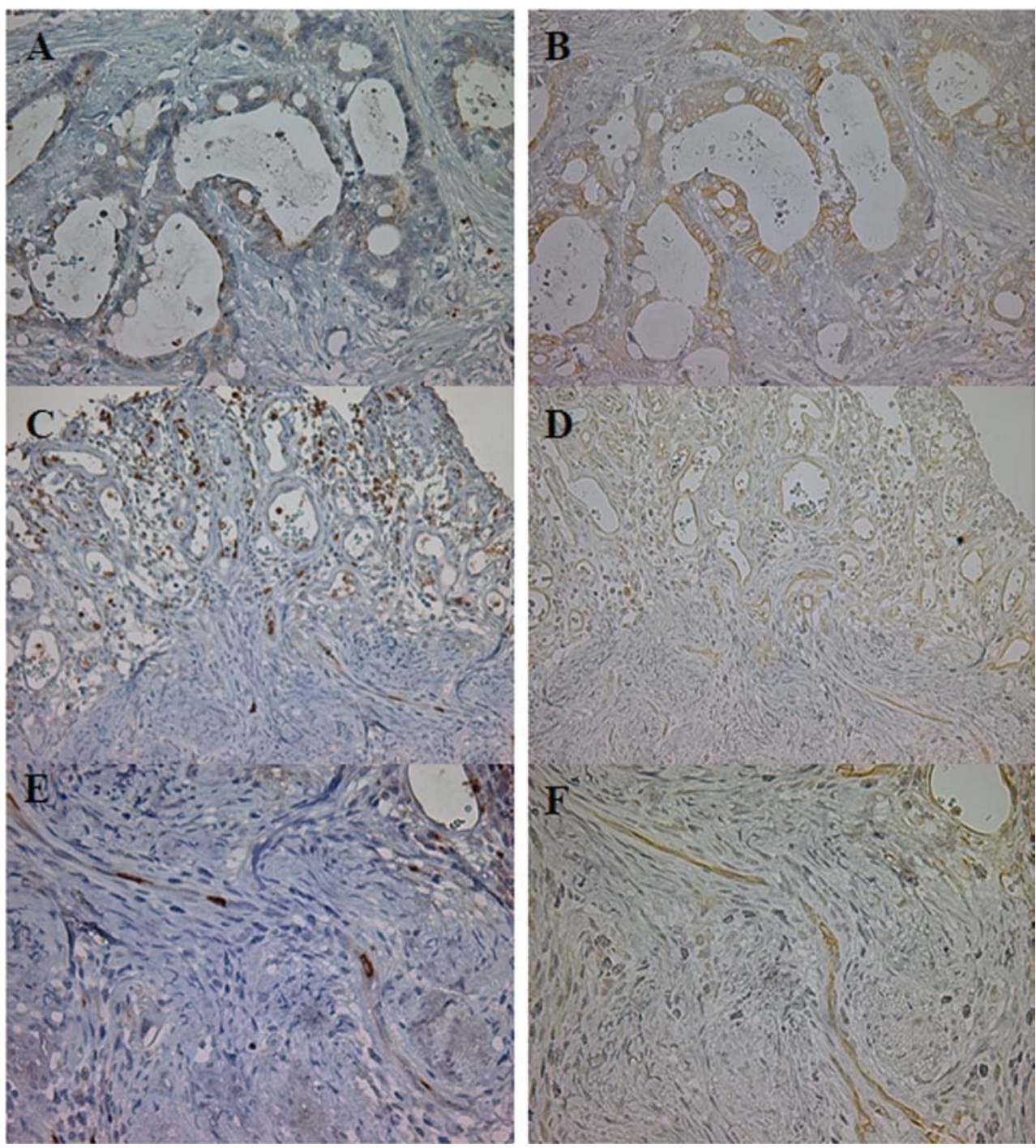

Figure 2. FAP- $\alpha$ (A) and SDF-1 (B) expression in residual cancer cells. Both FAP- $\alpha$ (C) and SDF-1 (D) are expressed in endothelial cells. FAP- $\alpha$ (E) and SDF-1 (F) expression in activated fibroblasts (E and F). Original magnification, x200 (A-D), x400 (E and F).

factor (22). Additionally, Karnoub et al showed that the co-injection of breast cancer cells and bone marrow-derived mesenchymal stem cells promoted their metastatic activity via signaling through the chemokine CCL5 in an in vivo study (23). This result suggests a direct pro-metastatic effect of CAFs. Therefore, CAFs play an important role in both tumor progression and regulation of the tumor microenvironment.

Certain studies have suggested that in colorectal cancer, CAFs are associated with poor prognosis and distant metastasis $(4,5,24)$. However, the evaluation of FAP- $\alpha$ and SDF-1 expression as CAF-associated markers and the association of their expression with clinicopathological variables in rectal cancer after CRT, have not been previously reported. In the present study, we found that the expression of FAP- $\alpha$ and SDF-1 in residual rectal cancer stroma after CRT was associated with distant recurrence and poor prognosis, although the rate of detection of their gene expressions was very low. Furthermore, we found that FAP- $\alpha$ and SDF-1 expression levels exhibited a significant positive correlation to each other in residual cancer stroma after CRT. Immunohistochemical results demonstrated that these proteins were expressed in activated fibroblasts. These results suggest that CAFs also play an important role in distant recurrence in rectal cancer after CRT. Hwang et al demonstrated that CAFs can influence chemo- and radio-sensitivity by using pancreatic cancer cells co-cultured in CAF-conditioned medium (25). However, no significant association between FAP- $\alpha$ and SDF-1 gene expression and histopathological response after CRT were observed in the present study.

Residual cancer cells were separated from stromal tissue using microdissection to enable accurate evaluation of FAP- $\alpha$ and SDF-1 gene expression in stromal tissue. We speculated that mRNA levels in stromal tissue might affect serum protein levels if these gene products are host-derived factors that promote re-growth and distant metastasis after CRT. While a correlation was observed between the SDF-1 mRNA level in stromal tissue and serum SDF-1 levels, no such correlation was found for FAP- $\alpha$. Additionally, patients with elevated serum SDF-1 concentration had equally poor overall survival as those with positive stromal SDF-1 gene expression. One possible reason for these different results in FAP- $\alpha$ and SDF-1 is that SDF-1 is one of many chemokines, while FAP- $\alpha$ is a 
cell-surface serine protease that acts only locally. Our results suggest that serum SDF-1 levels can reflect the local microenvironment surrounding residual cancer cells.

Many studies have reported that FAP- $\alpha$ expression in stromal tissue is correlated with tumor invasion and metastasis in colorectal cancer based on immunohistochemical analysis $(26,27)$. Our results also suggest that FAP- $\alpha$ expression can be used to predict poor prognosis in rectal cancer patients who have undergone pre-operative CRT.

The origin of CAFs has been suggested to be local fibroblasts or bone marrow-derived cells that are recruited into the developing tumor and adopt a CAF phenotype. These cells originate from epithelial or endothelial cells (4). Epithelialmesenchymal transition (EMT) is known as one potential mechanism of migration, invasion and metastasis of cancer cells. EMT facilitates cell migration and metastasis by the conversion of epithelial-derived cancer cells to a more mesenchymal-like state $(5,22,28)$. Zeisberg et al suggested that endothelial-mesenchymal transition should be categorized as a specialized form of EMT as a source for CAFs (29). In this study, FAP- $\alpha$ and SDF-1 were commonly expressed in residual cancer cells, endothelial cells and activated fibroblasts in the stroma, although a small number of fibroblasts displayed both FAP- $\alpha$ and SDF-1 staining in cancer stroma tissue compared to other fibroblasts. Our immunohistochemical findings suggest that CAFs could be derived from endothelial cells. As certain reports have suggested the occurrence of radiationinduced EMT (30), we believe that CAFs could be associated with tumor re-growth and distant recurrence in rectal cancer after CRT. In in vitro studies, Onoue et al demonstrated that the SDF-1/CXCR4 axis is involved in EMT in oral squamous cell carcinoma (31). We believe that SDF-1 also strongly contributes to EMT.

FAP- $\alpha$ antibody immunotherapy as well as the inhibition of the platelet-derived growth factor receptor and TGF- $\beta$ have been suggested as therapeutic strategies that target $\mathrm{CAF}$ recruitment or CAF-derived tumorigenic signals (32-34). In the near future, such CAF-targeted therapies could be established.

In rectal cancer, pre-operative CRT and TME result in significantly decreased local recurrence and significantly increased survival rates. However, further improvement in prognosis cannot be achieved in the absence of control of distant recurrence after pre-operative CRT. The 'seed and soil' hypothesis has been suggested as one explanation for distant metastasis (35). To control distant recurrence, both the 'seed' and the 'soil' should therefore be targeted. Controlling the condition of the cancer stroma, including CAFs, could be a useful strategy for preventing distant recurrence after CRT in rectal cancer. We plan to investigate the expression of various genes in the stromal tissue of metastatic sites, such as the liver and lung.

The data reported in this study should be interpreted with some caution. Major limitations included the small number of patients $(n=52)$, particularly those patients with distant recurrence $(n=8)$, as well as the retrospective nature of the study. We believe that a larger study population and long-term follow-up will allow us to validate the conclusions presented here.
In conclusion, FAP- $\alpha$ and SDF-1 expression was involved in tumor re-growth and recurrence, and the control of CAFs could be effective for preventing distant recurrence in rectal cancer patients treated with pre-operative CRT.

\section{Acknowledgements}

The authors would like to thank Motoko Ueeda and Yuka Kato for providing excellent technical assistance.

\section{References}

1. Sauer R, Becker H, Hohenberger W, et al: Preoperative versus postoperative chemoradiotherapy for rectal cancer. N Engl J Med 351: 1731-1740, 2004.

2. Bosset JF, Collette L, Calais G, et al: Chemotherapy with preoperative radiotherapy in rectal cancer. N Engl J Med 355: 1114-1123, 2006

3. Guillem JG, Chessin DB, Cohen AM, et al: Long-term oncologic outcome following preoperative combined modality therapy and total mesorectal excision of locally advanced rectal cancer. Ann Surg 241: 829-838, 2005.

4. Ostman A and Augsten M: Cancer-associated fibroblasts and tumor growth - bystanders turning into key players. Curr Opin Genet Dev 19: 67-73, 2009.

5. Sund M and Kalluri R: Tumor stroma derived biomarkers in cancer. Cancer Metastasis Rev 28: 177-183, 2009.

6. Orimo A and Weinberg RA: Stromal fibroblasts in cancer: a novel tumor-promoting cell type. Cell Cycle 5: 1597-1601, 2006.

7. Bhowmick NA, Neilson EG and Moses HL: Stromal fibroblasts in cancer initiation and progression. Nature 432: 332-337, 2004.

8. Finak G, Bertos N, Pepin F, et al: Stromal gene expression predicts clinical outcome in breast cancer. Nat Med 14: 518-527, 2008.

9. Park JE, Lenter MC, Zimmermann RN, Garin-Chesa P, Old LJ and Rettig WJ: Fibroblast activation protein, a dual specificity serine protease expressed in reactive human tumor stromal fibroblasts. J Biol Chem 274: 36505-36512, 1999

10. Rettig WJ, Su SL, Fortunato SR, et al: Fibroblast activation protein: purification, epitope mapping and induction by growth factors. Int J Cancer 58: 385-392, 1994.

11. Skubitz KM and Skubitz AP: Gene expression in aggressive fibromatosis. J Lab Clin Med 143: 89-98, 2004.

12. Huang Y, Wang S and Kelly T: Seprase promotes rapid tumor growth and increased microvessel density in a mouse model of human breast cancer. Cancer Res 64: 2712-2716, 2004.

13. Lee J, Fassnacht M, Nair S, Boczkowski D and Gilboa E: Tumor immunotherapy targeting fibroblast activation protein, a product expressed in tumor-associated fibroblasts. Cancer Res 65: 11156-11163, 2005.

14. Muller A, Homey B, Soto H, et al: Involvement of chemokine receptors in breast cancer metastasis. Nature 410: 50-56, 2001.

15. Orimo A, Gupta PB, Sgroi DC, et al: Stromal fibroblasts present in invasive human breast carcinomas promote tumor growth and angiogenesis through elevated SDF-1/CXCL12 secretion. Cell 121: 335-348, 2005.

16. Salvucci O, Yao L, Villalba S, Sajewicz A, Pittaluga S and Tosato G: Regulation of endothelial cell branching morphogenesis by endogenous chemokine stromal-derived factor-1. Blood 99: 2703-2711, 2002.

17. Matsusue R, Kubo H, Hisamori S, et al: Hepatic stellate cells promote liver metastasis of colon cancer cells by the action of SDF-1/CXCR4 axis. Ann Surg Oncol 16: 2645-2653, 2009.

18. Yoshitake N, Fukui H, Yamagishi H, et al: Expression of SDF-1 alpha and nuclear CXCR4 predicts lymph node metastasis in colorectal cancer. Br J Cancer 98: 1682-1689, 2008.

19. Yoshikawa R, Kusunoki M, Yanagi H, et al: Dual antitumor effects of 5-fluorouracil on the cell cycle in colorectal carcinoma cells: a novel target mechanism concept for pharmacokinetic modulating chemotherapy. Cancer Res 61: 1029-1037, 2001.

20. Japanese Society for Cancer of the Colon and Rectum: General Rules for Clinical and Pathological Studies on Cancer of the Colon, Rectum and Anus. 7th edition. Kanehara \& Co., Tokyo, 2006. 
21. Bijwaard KE, Aguilera NS, Monczak Y, Trudel M, Taubenberger JK and Lichy JH: Quantitative real-time reverse transcription-PCR assay for cyclin D1 expression: utility in the diagnosis of mantle cell lymphoma. Clin Chem 47: 195-201, 2001.

22. Potenta S, Zeisberg E and Kalluri R: The role of endothelial-tomesenchymal transition in cancer progression. Br J Cancer 99: $1375-1379,2008$.

23. Karnoub AE, Dash AB, Vo AP, et al: Mesenchymal stem cells within tumour stroma promote breast cancer metastasis. Nature 449: 557-563, 2007.

24. Koukourakis MI, Giatromanolaki A, Harris AL and Sivridis E: Comparison of metabolic pathways between cancer cells and stromal cells in colorectal carcinomas: a metabolic survival role for tumor-associated stroma. Cancer Res 66: 632-637, 2006.

25. Hwang RF, Moore T, Arumugam T, et al: Cancer-associated stromal fibroblasts promote pancreatic tumor progression. Cancer Res 68: 918-926, 2008.

26. Henry LR, Lee HO, Lee JS, et al: Clinical implications of fibroblast activation protein in patients with colon cancer. Clin Cancer Res 13: 1736-1741, 2007.

27. Iwasa S, Jin X, Okada K, Mitsumata M and Ooi A: Increased expression of seprase, a membrane-type serine protease, is associated with lymph node metastasis in human colorectal cancer. Cancer Lett 199: 91-98, 2003.

28. Tse JC and Kalluri R: Mechanisms of metastasis: epithelial-to-mesenchymal transition and contribution of tumor microenvironment. J Cell Biochem 101: 816-829, 2007.
29. Zeisberg EM, Potenta S, Xie L, Zeisberg M and Kalluri R: Discovery of endothelial to mesenchymal transition as a source for carcinoma-associated fibroblasts. Cancer Res 67: 10123-10128, 2007.

30. Tsukamoto H, Shibata K, Kajiyama H, Terauchi M, Nawa A and Kikkawa F: Irradiation-induced epithelial-mesenchymal transition (EMT) related to invasive potential in endometrial carcinoma cells. Gynecol Oncol 107: 500-504, 2007.

31. Onoue T, Uchida D, Begum NM, Tomizuka Y, Yoshida H and Sato M: Epithelial-mesenchymal transition induced by the stromal cell-derived factor-1/CXCR4 system in oral squamous cell carcinoma cells. Int J Oncol 29: 1133-1138, 2006.

32. Loeffler M, Kruger JA, Niethammer AG and Reisfeld RA: Targeting tumor-associated fibroblasts improves cancer chemotherapy by increasing intratumoral drug uptake. J Clin Invest 116: 1955-1962, 2006.

33. Pietras K, Ostman A, Sjoquist M, et al: Inhibition of plateletderived growth factor receptors reduces interstitial hypertension and increases transcapillary transport in tumors. Cancer Res 61: 2929-2934, 2001

34. Naber HP, ten Dijke P and Pardali E: Role of TGF-beta in the tumor stroma. Curr Cancer Drug Targets 8: 466-472, 2008.

35. Fidler IJ: The pathogenesis of cancer metastasis: the 'seed and soil' hypothesis revisited. Nat Rev Cancer 3: 453-458, 2003. 